\title{
Strategic Plan as a Tool for Performance Management in the Tanzanian Public Sector
}

\author{
Stella Malangalila Kinemo \\ School of Public Administration and Management, Mzumbe University, Morogoro, Tanzania
}

Email address:

smkinemo@mzumbe.ac.tz

\section{To cite this article:}

Stella Malangalila Kinemo. Strategic Plan as a Tool for Performance Management in the Tanzanian Public Sector: Journal of Human Resource Management. Vol. 8, No. 3, 2020, pp. 146-151. doi: 10.11648/j.jhrm.201200803.15

Received: May 3, 2020; Accepted: June 22, 2020; Published: July 4, 2020

\begin{abstract}
The study empirically examined the effectiveness of the implementation of strategic plan in Tanzanian public sector specifically in Ilala Municipality. The study employed case study design and mixed research approaches of qualitative and quantitative. Data was collected using interview, questionnaire and documentary review and was analyzed using qualitative and quantitative analysis. The findings revealed that there is poor involvement of staff in the formulation of strategic plan, inadequate financial ability, inadequate number of staff, lack of expertise in some fields, lack of autonomy in revenue collection and recruitment of staff, inconducive working environment, and budgetary deficit in the implementation of the strategic plan. To enhance effective implementation of strategic plan the study recommends involving more staff in the planning process especially at the stage of identifying strength, weaknesses, opportunities and challenges of the municipality. With respect to lack of autonomy in revenue collection and recruitment of staff it is recommended that the Ilala municipality should be given more autonomy rather than being interfered by the central government. The intergovernmental transfers of funds to Ilala municipality should be made on time without delay for effective implementation of strategic plan. The study argues that unless the obstacles to the implementation of strategic plan are addressed, its implementation will remain ineffective.
\end{abstract}

Keywords: Performance Management, Strategic Plan, Public Sector

\section{Introduction}

Performance management system is the method used to measure the performance of employees by aligning organizations' mission, and objectives with existing resources such as human resource, funds, working facilities, raw materials etc. It is being argued by authors that the purpose of performance management is to increase performance in which employees take responsibility for the continuous improvement of an organization activities. Performance management focus on performance improvement in order to achieve the organization's objectives and strategic goals. It is used as a means of achieving objectives of the organization from the teams and individuals by measuring performance within an agreed framework of goals, standards and competence requirements. The purpose of the Performance Management System (PMS) in Tanzania is to improve the efficiency and effectiveness in public service delivery. In Tanzania a Result Based Management
(RBM) was introduced using Performance Improvement Model (PIM). This is an integrated approach to performance management with interlinked four stage processes and nine elements. All public service institutions are required to plan implement, monitor, evaluate, and report on performance, and carry out performance reviews. From the year 2000 to 2006 PIM was installed in all Ministries, independent Departments, Executive Agencies and Regional Secretariats. For the purpose of enabling institutionalization of a performance management system The Tanzanian Public Service introduced tools for performance management including strategic and operational planning, client service charters, service delivery surveys, self-assessment programs, performance budgets, the introduction of Open Performance Review and Appraisal System (OPRAS) and comprehensive Monitoring and Evaluation (M\&E) system. For the purpose of this paper only one tool which is strategic planning was studied.

Although Tanzania public organizations including 
municipalities are required by planning and budgeting guidelines [12] to have a five years strategic plans, however, its implementation is not effective as per audit reports for four consecutive years from the Controller and Auditor General for financial years 2013/2014; 2014/2015; 2015/2016 and 2016/2017 [13-16]. The report revealed that, implementation of strategic plans in public organizations were ineffective with indications of poor linkage of budgets and strategic plans, lack of clarity, poor communication of strategies, lack of performance indicators, and inadequate monitoring and evaluation. This implies that poor implementation of strategic plans in public organizations may result to non-implementation of the intended strategies and targets. The problem of implementation of strategic plans in local authorities is mostly seen in transforming the strategic plan into actions. Despite the efforts to formulate and implement the strategic plans in local government which includes rural and urban local authorities there is still ineffective implementation of targets and strategies. Therefore, the purpose of this study was to investigate factors affecting implementation of strategic plan in Ilala municipality.

\section{Literature Review}

\subsection{Strategic Plan}

A strategy is a coordinated set of actions that fulfil firm's objectives and purposes [1]. It is formulated to align the resources and competences aimed at accomplishing the vision, goals and expectations of stakeholder [6]. Strategic plan is a process that charts out an institution's broad direction forward. It's a step by step guide that map out how the organization will reach its goals in the future [3]. Any organization needs to have strategic plan for the purpose of implementing its targets. It is a plan for achieving the organisation's long-term performance targets for the purpose of fulfilling the desired mission. Strategic plan shows an organization's broad direction and how it will reach its goals in the future [3]. Any strategic plan is designed to meet targets of the organization and has time frame.

The main purpose of the formulation and implementation of strategies is to enable the firm to attain its long-term and short-term mission [2]. Strategic plans should address organizations' mission, vision, situational analysis, objectives, strategies, targets, indicators, monitoring and evaluation of targets and indicative budgets. To ensure the strategy is executed as planned, top executives should not consider that lower level managers have the same perceptions about executing strategies, and their importance and urgency, but rather, they must work together with employees to attain these goals [7]. Studies have shown that implementation of strategic plans is faced by many challenges. For instance, [9] in his study observed that lack of adequate financial resources was a significant challenge in strategy implementation in municipalities. Other studies have found that implementation of strategies in some organizations is highly influenced by management commitment and availability of resources for strategic decision making [4]. The observation is also witnessed in public sector in Tanzania where rural and urban local authorities are facing several challenges during implementation of strategic plan. [10] observed that there a need to get many more people involved in execution.

\subsection{Resource Based Theory}

In this study the theory of Resource Base Theory is utilized to show the factors contributing to effectiveness of the strategic plan implementation. A Resource - Based Theory is used to bring into attention the significance of resources in the organization and the administration of the resources. The theory is based on the assumptions that organization's resources are determining factors of improving performance in the organization. The assumption is that the effectiveness of implementation of strategic plan is caused by presence of the required resources in the organization. Organizations may also be seen as bundles of human, physical and capabilities which creates sustainable competitive advantage [3]. The theory has shown that the required resources by organizations include funds, qualified human resources, technology capacity, inputs, and the loyalty of the customers. Therefore, given the importance of resources in the process of implementation of strategic plans, this theory is linked to this study.

In regard to this study human resources, availability of funds, working facilities, and awareness of staff were studied to see how they affect implementation of the strategic plan in Ilala municipality.

\subsection{Conceptual Framework}

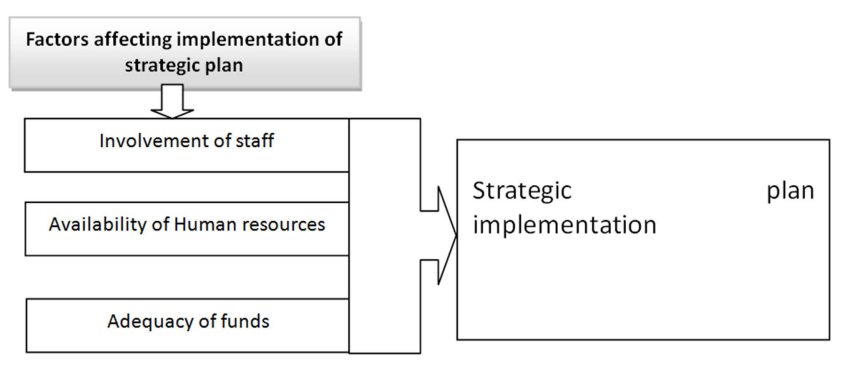

Figure 1. Conceptual; Framework.

Figure 1 shows the conceptual framework of the study. The underlying assumption for the study is that availability of staff, working environment, adequacy of finance, awareness and involvement of staff contributes to the effectiveness of the implementation of strategic plan. All these were regarded as independent variables. The successful implementation of strategic plan was regarded as dependent variable. The conceptual framework of the study does not focus on the causal- effect relationship between dependent variable and independent variables of the study. It shows the independent variables linkage to the effectiveness of the strategic plan implementation. 


\section{Methodology}

This study employed a case study design conducted in Ilala municipal Council located in Dar es Salaam City of Tanzania. The municipality is one of the six municipalities that constitute Dar er Saalam City. Ilala Municipal Council was purposively selected due to the presence of strategic Plan of the year 2017/2018-2021/2022 which currently is under implementation. Only staff working at the headquarter were involved in the study where the targeted population of the study comprised 175 staff. The respondents in this study involved 64 staff of Ilala municipality. Out of 64 respondents 35 were staff from different departments and eight (8) were heads of departments as key informants. Random sampling was used to select staff while purposive sampling was used in selecting heads of departments who were the key informants. The key informants were selected basing on their knowledge and information on the existing strategic plan of 2017/2018$2021 / 2022$. The in-depth interviews were conducted to key informants and information on emerging issues during formulation and implementation of strategic plan. Documentary review was done by reviewing Municipal Strategic plan of 2017/2018-2021/2022 and information on the constraints in the implementation of strategic plan was obtained. The questionnaire was used to collect data on the financial ability, working environment and staff adequacy in implementing strategic Plan. Qualitative and quantitative data were collected and analyzed using content analysis and descriptive analysis respectively. The descriptive statistical analysis involved the use of frequencies and percentages to interpret findings of the study.

\section{Findings and Discussion}

The study found that, there were internal and external factors affecting implementation of strategic plan of the municipality including lack of awareness of employees on the existence of strategic plan, employee's involvement in the process of preparing strategic plan, inadequate financial ability, lack of competencies and capability needed to successful implementation of strategic plan.

\subsection{Awareness of Staff on the Process of Strategic Plan Formulation}

The study investigated the awareness of staff on the process of strategic plan formulation. As Table 1 indicate out of 64 total number of respondents $37(57.81 \%)$ staff were not aware on the process of formulation of strategic plan, 7 (10.94\%) staff were somehow aware and 20 (31.25\%) staffs were aware on the same.

Table 1. Awareness of staffs on the process of strategic plan formulation.

\begin{tabular}{lll}
\hline Response & Frequency & Percentage \\
\hline Not aware & 37 & $57.8 \%$ \\
Somehow aware & 7 & $10.94 \%$ \\
Aware & 20 & $(31.25 \%)$ \\
\hline
\end{tabular}

These findings imply that, even though staffs were the key implementers of the strategic plan but majority of them were not aware on the formulation of strategic plan. The findings indicate that strategic plan formulation involved only management of the municipality such as heads of departments and councilors. This finding indicates that unawareness of staff leads to non-commitment of staff on the implementation of the strategic plan. Commitment to the implementation of strategic plan will grow if only staff work together and decide together on the plans to be implemented in the municipality. Staying committed to the implementation of strategic plan is one of the principles of success of municipality goals. This finding implies that plans which are planned and implemented in the municipality are superimposed on staff resulting to non-commitment.

\subsection{Staff Involvement in the Process of Strategic Plan Formulation}

It is very surprising that majority of staff were just implementors of strategic plans by receiving instructions and directives from their superiors. Respondents were asked whether they were involved in the process of formulating strategic plan of the municipality. The process involved situational analysis, developing objectives, strategies and targets which are final goods or services to be produced over a given period of time.

Findings revealed that, $42(65.63 \%)$ staffs out of 64 were not involved in the process of strategic plan formulation, and $22(34.38 \%)$ staffs were involved in the process of strategic plan formulation, where by $14(60.87 \%)$ out of 22 staff involved in the process of strategic plan formulation were top management and $8(39.13 \%)$ were employees. As shown in Table 2 .

Table 2. Staff involvement in the formulation of strategic plan $(N=64)$

\begin{tabular}{lll}
\hline Response & Frequency & Percentage \\
\hline Staff not involved & 42 & 65.63 \\
Staff involved & 22 & $34.38 \%$ \\
\hline
\end{tabular}

These findings imply that majority of the staff were not involved in the process of strategic plan formulation and this is an indication that there is lack of ownership of the strategic plan which eventually may affect commitment to its implementation. So that ownership of the strategic plan can be increased the process of formulating strategic plan for the municipality should be participatory involving all employees and other primary stakeholders. The perception that there is inadequate involvement of staff in the process of strategic plan is an indication that the management should involve all staff in the process instead of involving few staff.

One of interviewee stated that;

"I have more than 12 years now as an employee of Ilala municipal, but I have never attended any strategic plan meeting or being involved in strategic plan formulation"

This finding implies that non-involvement of staff in the formulation of municipal strategic plan is a common phenomenon and its only municipal top management and few staff who are involved in the process of setting strategic 
objectives and targets for the five years plan. This finding suggests that there is variation of the degree of participation by non-managerial employees in preparing strategic plan for the municipality. One of the key informants stated that;

"The preparation of strategic plan in our municipality does not include all staff and those who are involved are not committed in implementing the strategies hence we the employees are not motivated in implementing the strategies",

These findings have revealed that there is partial involvement of staff in the formulation of strategic plan. Ideally, all involved parties need to participate in the process of preparing strategic plan for the municipality. Involvement of staff in the formulation of strategic plan process will give staff the opportunity to share their knowledge and skills with others, improve teamwork among staff and eventually implement strategic plan successfully. The responsibility for strategic plan execution should not be limited only to heads of departments and councilors, but should also include all employees for efficiency of strategic plan implementation. The involvement should include all, staff in the municipality to increase their commitment in the implementation of the strategic plan. The added value of involving all staff in the formulation of strategic plan is that they tend to be more determined in the implementation of the strategic plan and active in contributing their support. Other scholars argue that poorly communicated objectives affect effective implementation and employees who are not well informed hinder the implementation of the strategic plan [5]. Furthermore, a study done by [10] also revealed that one of the challenges of implementing strategic plan is poor knowledge of the process and involvement in the formulation of the strategic plan.

\subsection{Shortage of Staff}

Competence entails behavior, knowledge and skills that enable employees to perform effectively and efficiently activities in the organization. In implementing strategic plan competence is highly needed for the success of the plans. Without competence it is almost difficult to put plans, strategies and targets into action to reach desired goals. It was found that Ilala municipality lack the right personnel with the required skills and competences to carry out the identified targerts effectively. Competence and shortage of staff in some areas were among the factors which affected the implementation of strategic plan. The study sought to find out the extent respondents were competent to implement the targets specified in the strategic plan. It was found that high percent of respondents agreed that employees had inadequate competencies and capability to implement some of the targets set by the municipality. One of the respondents explained that:

"The problem we are facing is lack of required qualified staff in some areas of set targets."

For instance, according to the Municipal Strategic Plan of 2017/2018-2021/2022 the Department of Human Resources has 338 employees, out of 724 required. Effective implementation of strategic plan requires sufficient number of staffs with competency. For effective implementation of strategic plan Ilala Municipality requires about 10191 employees to work in different departments. However according to Personal Emoluments estimates for the existing employees are $8438(82 \%)$ only compared to its requirements. For efficient and effective operation of strategic plan targets the availability of human resources is fundamental. The municipality is facing shortage of Social Welfare Officers at ward levels, inadequate reporting skills and record keeping skill at Mitaa (Streets) and Ward Development Committees. Furthermore, the autonomy of the municipality for recruitment is limited to identification of vacancies and budgeting for the same. The recruitment of staff particularly the high-level cadres is executed by the Public Service Recruitment Secretariat at the national level. All civil servants in Tanzania including staff of municipalities are recruited by Public Service Recruitment Secretariat (PSRS) excluding directors of the authorities. The municipality and other local authorities have no mandate to recruit except for the few staff. The use of Recruitment Secretariat limits the municipality to recruit the required staff because of the delays in filling the vacancies. Lack of autonomy to recruit staff limit implementation of some of the strategies and targets identified in the strategic plan. The overall conclusion is that the institutional framework which insist on seeking permission from central government to recruit constrain the implementation of the strategic plan.

Furthermore, it was observed that there was lack of Monitoring and Evaluation software for effective reporting and poor record keeping. These findings imply that ward reports are not written well and timely leading to wrong information and wrong decision making. Lack of correct records from relevant departments and wards hinder effective implementation of strategic plan. The result concurs with other scholars who argued that organizational resources are important during implementation of strategic plan [4].

\subsection{Working Environment}

Working environment in the public sector plays an important role in the implementation of strategic plans. It is well known that the quality of the employee's work environment has an influence on the employee's motivation and eventually performance in the implementation of strategic plan. For effective implementation of strategic plans, the work environment should include required equipment, safe physical space and well-designed organized offices. Basing on strategic plan of Ilala municipality it was found that the working environment in the wards and streets was challenging due to limited offices, transport facilities, houses and working tools to majority of municipality staff. Lack of conducive environment at the municipality has made difficulties in spreading community development and social welfare knowledge and skills. Furthermore, in the area of education it was found that there was shortage of teaching and learning materials such as textbooks, shortage of 2446 
tables and 2446 chairs for students and shortage of 331 classrooms. This is an indication that the constraints that are faced by the municipality eventually affect implementation of strategic plan in the sectoral areas. It was also found that lack of vehicles for monitoring and evaluating planned activities affect implementation of strategic plan. Monitoring and evaluation of implementation of strategic plans help to quantify the attainment of strategies and targets and whether they were implemented as planned. These findings suggest that the working environment of the staff working in the municipality is not good. The absence of a positive work environment may make municipality staff uncomfortable to implement the strategic plan effectively.

\subsection{Inadequate Financial Ability}

The study investigated whether the municipality had adequate funds for the implementation of the strategic plan. Respondents were asked whether the municipality had adequate funds for the implementation of planned targets as stipulated in the strategic plan. The results in Table 1 revealed that out of 64 respondents, the majority $22(62.9 \%)$ respondents strongly disagreed that the municipality had adequate funds, $10(28.6 \%)$ respondents disagreed, and 3 $(8.6 \%)$ respondents agreed. It was found that inadequacy of funds in the municipality limited the implementation of its plans. It was revealed that Ilala municipality had inadequate financial ability to implement its strategic plan. The underlying problem of poor implementation of some targets was due to financial constraints facing the municipality. The inadequacy of financial ability was attributed by limited development budget and insufficient own sources of revenues which have led to poor implementation of the strategic plan. The study confirms that in the municipality there is insufficient funds in implementing activities of strategic plan. [10] in his study found that inadequate funding from the government and other sources is a challenge as there are no adequate fund. Furthermore, empirical evidence shows that in reality, the local government authorities are financially incapable as $80-90 \%$ of their recurrent budget depends on intergovernmental transfers to fund their activities [8].

Table 3. Adequacy of funds for the implementation of strategic plan.

\begin{tabular}{lll}
\hline Response & Frequency & Percentage \\
\hline Strongly disagreed there are adequate & 22 & 62.9 \\
funds & & $28.6 \%$ \\
Disagreed there are adequate funds & 10 & 8.6 \\
\hline Agreed there are adequate funds & 3 & \\
\hline
\end{tabular}

The government of Tanzania has been implementing local government reforms since 1990s, including fiscal decentralization. Fiscal decentralization is a system that involves transfer of fiscal responsibilities and local government finances from central government to subnational government that emphasizes equitable and transparency revenue mobilization and capital development grants [11]. Fiscal decentralization aimed at allowing participatory planning process and also to have full autonomy in revenue mobilization and local spending. The local government mandate to collect and spend own revenue including was interfered by national level including collection of property tax and land rent. The Local Government establishing Acts provide the municipality with autonomy in revenues collection and expenditure however the sources of revenue have always been narrowed. The centralization of the sources of revenue has limited the capacity of the municipality to implement the strategic plan. This state has affected Ilala municipality and other Local Government authorities to deliver services basing on the strategies and targets of the strategic plans. Interviews with key informants revealed that there were delays in development grants disbursement from the Central Government for implementation of development project which were part of the strategic plan. It was also found that the amount which was supposed to be disbursed by the central government to the municipality were not disbursed or disbursed in small amount. This led to either delay or non-implementation of targets identified in the strategic plan. Inadequate financial ability of the municipality has a proportionately effect on the implementation of strategic plan. These findings imply that implementation of the set targets and strategies depend more on government funding.

\section{Conclusion and Recommendations}

This paper concludes that there is poor involvement of staff in the formulation of strategic plan in the municipality. There is inadequate number of staff and lack of expertise in some fields as indicated in the findings. The working environment at the lower level of management especially in wards is not conducive due to lack of offices and working facilities. Fiscal autonomy is limited and controlled by the central government and budgetary deficit is a common feature in the municipality and this has affected the implementation of the strategic plan.

This paper recommends that the municipality should involve more staff in the planning process especially at the stage of identifying strength, weaknesses, opportunities and challenges of the municipality of the strategic plan. The involvement of staff should also include identifying strategies and targets of the municipality while formulating a strategic plan. The involvement will increase commitment of staff in the implementation of plans of the municipality. With respect to lack of autonomy in revenue collection and recruitment of staff it is recommended that the Ilala municipality and other local authorities should be given more autonomy rather than being interfered by the central government. The intergovernmental transfers of funds to Ilala municipality should be made on time without delay for effective implementation of strategic plan. 


\section{References}

[1] Demirkaya, Y. (2015). Strategic planning in the Turkish public sector. Transylvanian Review of Administrative Sciences, 1529. De Vries. M., \& Nemec, J. 2013. Public sector reform

[2] Elbanna, S., Andrews, R., \& Pollanen, R. (2016). Strategic planning and implementation success in public service organizations: Evidence from Canada, Public Management Review, 18 (7), 1017-1042.

[3] Ferlie, E., \& Ongaro, E. (2015). Strategic management in public services organizations: Concepts, schools, and contemporary issues. London: Routledge.

[4] Gachua, M., \& Mbugua, D. (2016). Factors Affecting Strategy Implementation in Private Universities in Kiambu County, Kenya; International Journal of Management and Commerce Innovations, 4, (2), 118-122.

[5] Genc, E. (2017). Strategy Implementation, Organizational Culture and Performance in Turkish Local Government, Unpublished PhD Thesis, Cardiff University.

[6] Joyce, P., \& Drumaux, A. (2014). Strategic management in public organizations: European practices and perspectives. New York: Routledge.

[7] Koech, A. K \& Were, S. (2016). Factors Influencing Strategy Implementation at the National Treasury-Kenya; The Strategic Journal of Business \& Change Management, 4 (15), 269-288.
[8] Lameck WU (2017) Decentralisation and Serviced Delivery, PhD thesis, VU University, Amsterdam

[9] Nkosi, S. M. (2015). Factors Affecting Strategy Implementation: A Case Study of a Local Municipality in Mpumalanga Province, South Africa, European Journal of Business and Management, 7 (36), 2015 -2064.

[10] Raphael, C. (2018). Performance of Academic Staff in Public Technical Higher Education Institutions in Tanzania. Unpubllished PhD Thesis, Mzumbe University

[11] Satta, T and Pennink, B (2013) "Decentralization by Devolution in Tanzania; The role of Local Financial Management and Tax Revenues.

[12] URT. (2011) Guidelines for the Preparation of Plan and budget, Tanzania: Ministry of Finance.

[13] URT. (2015). Report of Public Authorities and other Bodies 2013/2014, Dar es Salaam, Controller \& Auditor General.

[14] URT. (2016). Report of Public Authorities and other Bodies 2014/2015, Dar es Salaam, Controller \& Auditor General.

[15] URT. (2017). Report of Public Authorities and other Bodies 2015/2016, Dar es Salaam, Controller \& Auditor General.

[16] URT. (2018). Report of Public Authorities and other Bodies 2016/2017, Dar es Salaam, Controller \& Auditor General. 